\title{
A Simplified Control Approach of AC-DC-TLBC for Bi-Polar DC Microgrid Applications
}

\author{
D. Sathish ${ }^{\mathrm{a}}$, A. Bhanuchandar ${ }^{\mathrm{b}}$, D. Harsha ${ }^{\mathrm{a}}$ and C. Srisailam ${ }^{\mathrm{a}}$ \\ A Department of EEE, Chaitanya Bharathi Institute of Technology (A), Gandipet, Hyderabad, T.S, India-500075. \\ ${ }^{B}$ Electrical Engineering, National Institute of Technology, Warangal, India,
}

Article History: Received: 11 January 2021; Accepted: 27 February 2021; Published online: 5 April 2021

\begin{abstract}
In this paper the main focus is to convert 3-Phase AC to DC and DC to 3-level Boost conversion for bipolar DC micro grid applications. The input side of AC-DC converter acts as active PWM rectifier and this can be controlled by using a new Min Max (MM) control algorithm to maintain the regulated DC link voltage. The DC link voltage is boosted according to the duty cycle along with voltage balance compensation algorithm in 3-L Boost (TLBC) converter. Hence the combination of two control approaches can provide better dynamic and steady state responses and the output results are carried out by MATLAB /Simulink environment.
\end{abstract}

Keywords: 3-L Boost converter (TLBC), Pulse Width Modulation (PWM), Min Max (MM) controller, Voltage Balance Controller (VBC).

\section{Introduction}

The integration of power electronic converters with non-conventional energy sources and usage of stored energy is rapidly increasing day-by-day (Zhong, 2013; Garikipati, 2021; Arunkarthikeyan, 2021). Traditionally the output voltage of a rectifier is controlled by Pulse Width Modulation (PWM) method. To minimize the harmonic distortion in the grid current and to achieve the bidirectional power flow in the converter, there are many control techniques being proposed. These control techniques helps to improve the power factor and maintaining the regulated DC bus Voltage (Dubey, 2013; Pavan, 2020; Balamurugan, 2020). In general the voltage generated at the generating station is $\mathrm{AC}$, which is given to the transmission system, rectifier Circuit. This rectifier circuit converts from AC voltage to DC voltage. To reduce the harmonic distortion, control the flow of $\mathrm{kVAr}$ and to improve the power factor of a system primarily depends upon the performance of the rectifier circuit (ChinnamahammadBhasha, 2020, Deepthi, 2019; Balamurugan, 2017). It is operated in two ways, namely passive method and active method. The passive method consists of diode rectifier circuit, reactors and capacitors. This circuit suffers from the limitations of low power factor and voltage cannot be increased above a particular level (Takahashi , 1995; Arunkarthikeyan, 2020). The Active method consists of switching elements like IGBTs (ChinnamahammadBhasha, 2020). The moderate value of switching frequency helps to obtain the power factor of the sinusoidal current nearer to unity and to reduce the input harmonic distortion but efficiency decreases (Hui; 2000; Tavakoli, 2016; Balamurugan, 2018). Many control algorithms have been proposed for 3-phase rectifiers to obtain better DC voltage profile. In most of the applications power factor improvement is the major concern, but in modern control technologies the adaptability of rectifier helps mainly to control the kVAR in the power system application (Ezhilarasi, 2020; Aroulanandam, 2020). Uni-polar DC micro grid provides only one voltage level. If the link in the grid system gets damaged the system completely comes to shutdown position. In bi-polar Micro Grid system customer has to select three voltages $+\mathrm{V}_{\mathrm{dc}},-\mathrm{V}_{\mathrm{dc}}$, and 2 Vdc. During the fault one of the DC pole voltage supplies the continuous power with two wires. So that security, loyalty, accessibility and quality of the power improves during faulty condition (Balamurugan, 2020; Latchoumi, 2020). Bipolar grid having three voltage levels provides much accessibility to the customers in order to connect various DC loads. For bipolar micro grid applications, the three level boost converters is used and this converter mainly helps to reduces the dv/dt stresses on switches as compared to the two level boost converter (Kowstubha, 2020; Garikapati, 2020; Bhasha, 2020; Pavan, 2020).The active PWM rectifier of the system uses complex algorithm for maintaining the good DC link voltage (Kowstubha, 2020; Chinnamahammad bhasha, 2020).

In this paper, the combination of active PWM rectifier with simple MM control algorithm and three level boost converters along with voltage balancing operation is proposed to overcome the above difficulties. The 
input and output side in the Fig.1 comprises of 3-phase active PWM rectifier and 3-L boost converter. The aim of the input converter is to convert alternating current to direct current by using the MM control algorithm

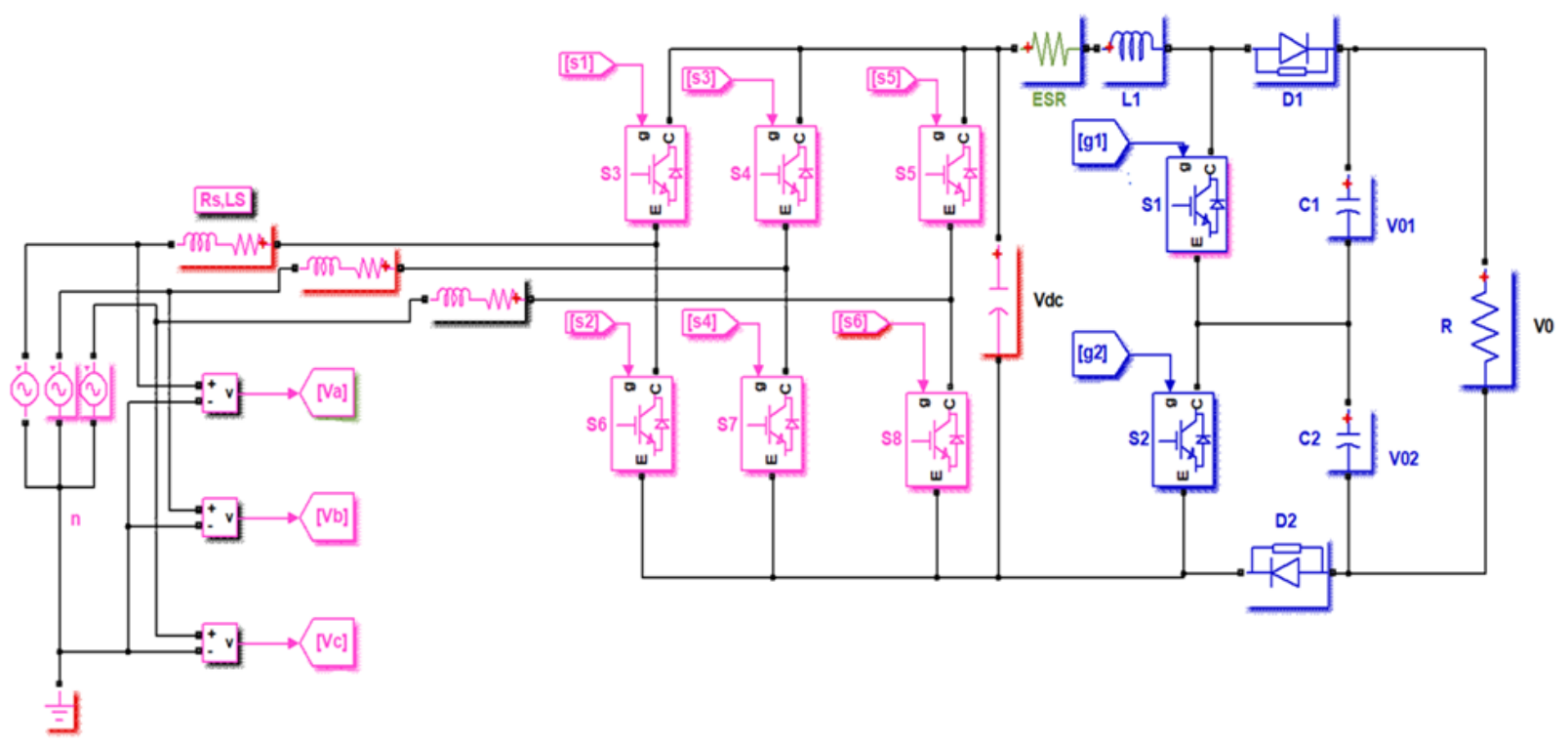

Figure 1. AC-DC-TLBC Circuit

\section{Main circuit diagram and its Control algorithm:}

\subsection{Control Algorithm for input converter:}

In the Fig. 2 the input phase voltages are sensed from the supply. The obtained three phase voltages are given to gain 4 and the output of gain 4 is connected to min max blocks. The addition of min, max blocks are given to gain 5 . The obtained gain 5 is subtracted from the gain 4 and the resultant is given to suitable gain value 6 , then desired control signals are produced. These control signals acts as modulating signal for SVM/extension of sine PWM. The resultant control signals are compared with repeating sequence along with desired switching frequency, hence required pulses are generated. In this way input rectifier maintains constant DC link output voltage, low current harmonic distortion at input side and also improves the p.f.
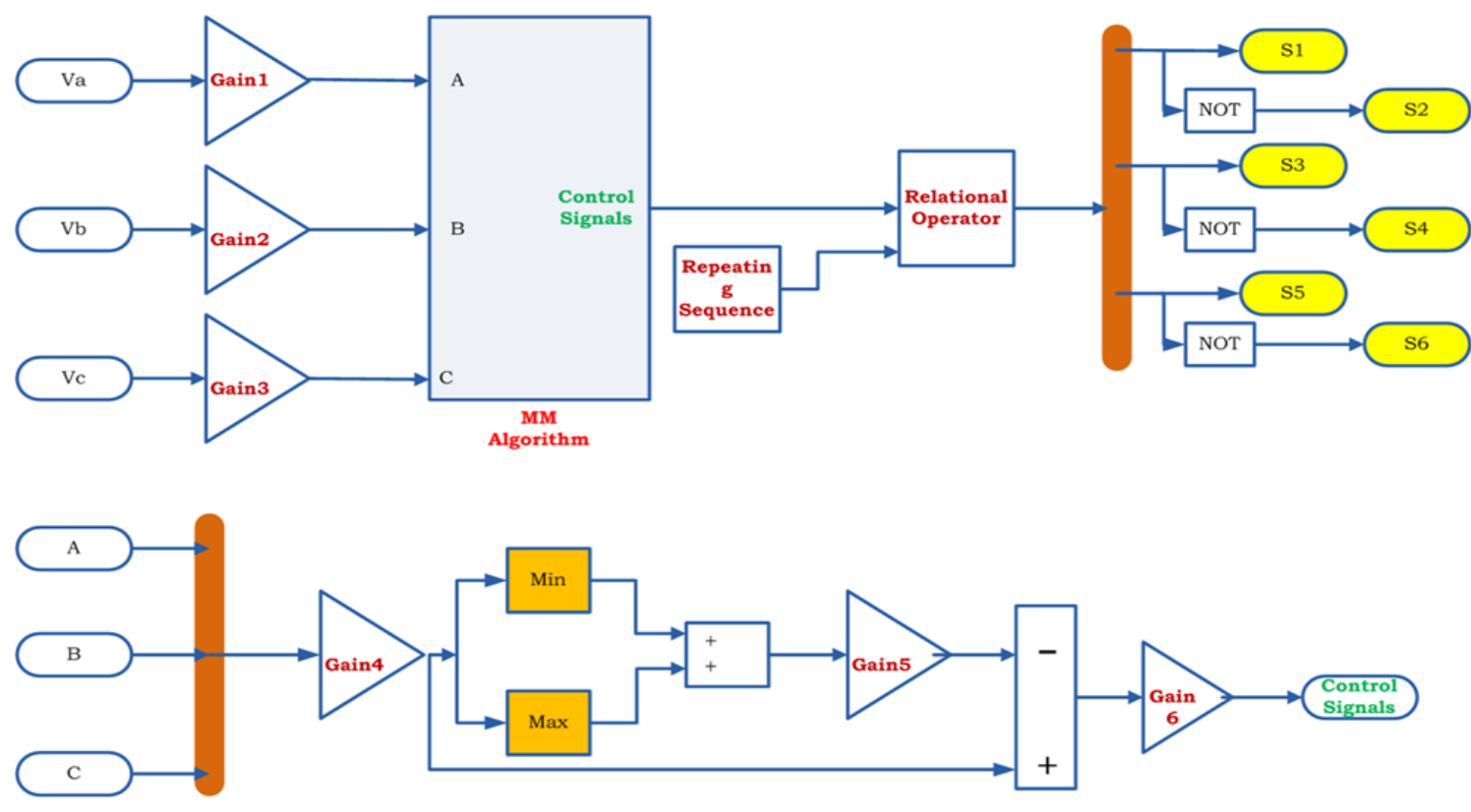

MM Algorithm

Figure 2. Control algorithm-AC to DC Converter (input side) 


\subsection{Operation of TLBC:}

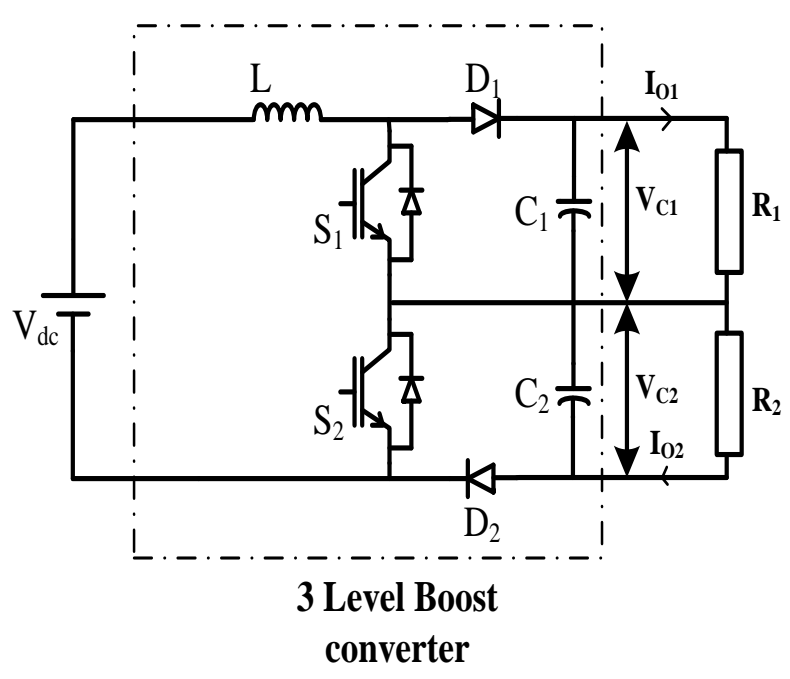

Figure 3. TLBC

The 3L-Boost converter shown in the Fig. 3 comprises of an inductor L, two IGBT switches and two diodes. The mid-point of the switching cell is connected to the midpoint of capacitors $\mathrm{C} 1$ and $\mathrm{C} 2$ and the voltages across them be $\mathrm{Vc1}$ and $\mathrm{Vc} 2$ respectively [14].The following are the characteristics of 3L DC-DC converters.

i) Each switching device is subjected to half the rated output voltage.

ii) The inductor size is reduced significantly due to increase switching frequency.

The output voltage $\left(\mathrm{V}_{\mathrm{o}}=\mathrm{Vc} 1+\mathrm{Vc} 2\right)$ expression as a function of duty cycle $(\mathrm{d})$, it is similar to that of classical boost converter and is given by,

$$
V_{o}=\frac{V_{d c}}{1-d}
$$

Based on the duty cycle the converter can be operated in the following two regions.

$$
\begin{gathered}
0.5 \leq d \leq 1 \text { or } V_{i} \geq \frac{V_{o}}{2} \text { Region }-I \\
0 \leq d \leq 0.5 \text { or } V_{i}<\frac{V_{0}}{2} \text { Region }-I I
\end{gathered}
$$

Depending on whether the S1 and S2 are in ON or OFF position, the DC- DC converter can have four different operating regions $(00,01,10$ and 11$)$. The voltage loop equations for the TLBC are given by,

$$
\begin{gathered}
\mathrm{L} \frac{\mathrm{di}_{\mathrm{L}}}{\mathrm{dt}}=\mathrm{V}_{\mathrm{dc}}-\left(\mathrm{V}_{\mathrm{C} 1}+\mathrm{V}_{\mathrm{C} 2}\right): \text { Mode-I } \\
\mathrm{L} \frac{\mathrm{di}_{\mathrm{L}}}{\mathrm{dt}}=\mathrm{V}_{\mathrm{dc}}-\mathrm{V}_{\mathrm{C} 1}: \text { Mode }-\mathrm{II} \\
\mathrm{L} \frac{\mathrm{di}_{\mathrm{L}}}{\mathrm{dt}}=\mathrm{V}_{\mathrm{dc}}-\mathrm{V}_{\mathrm{C} 2}: \text { Mode }-\mathrm{III} \\
\mathrm{L} \frac{\mathrm{di}_{\mathrm{L}}}{\mathrm{dt}}=\mathrm{V}_{\mathrm{dc}}: \text { Mode }-\mathrm{IV}
\end{gathered}
$$




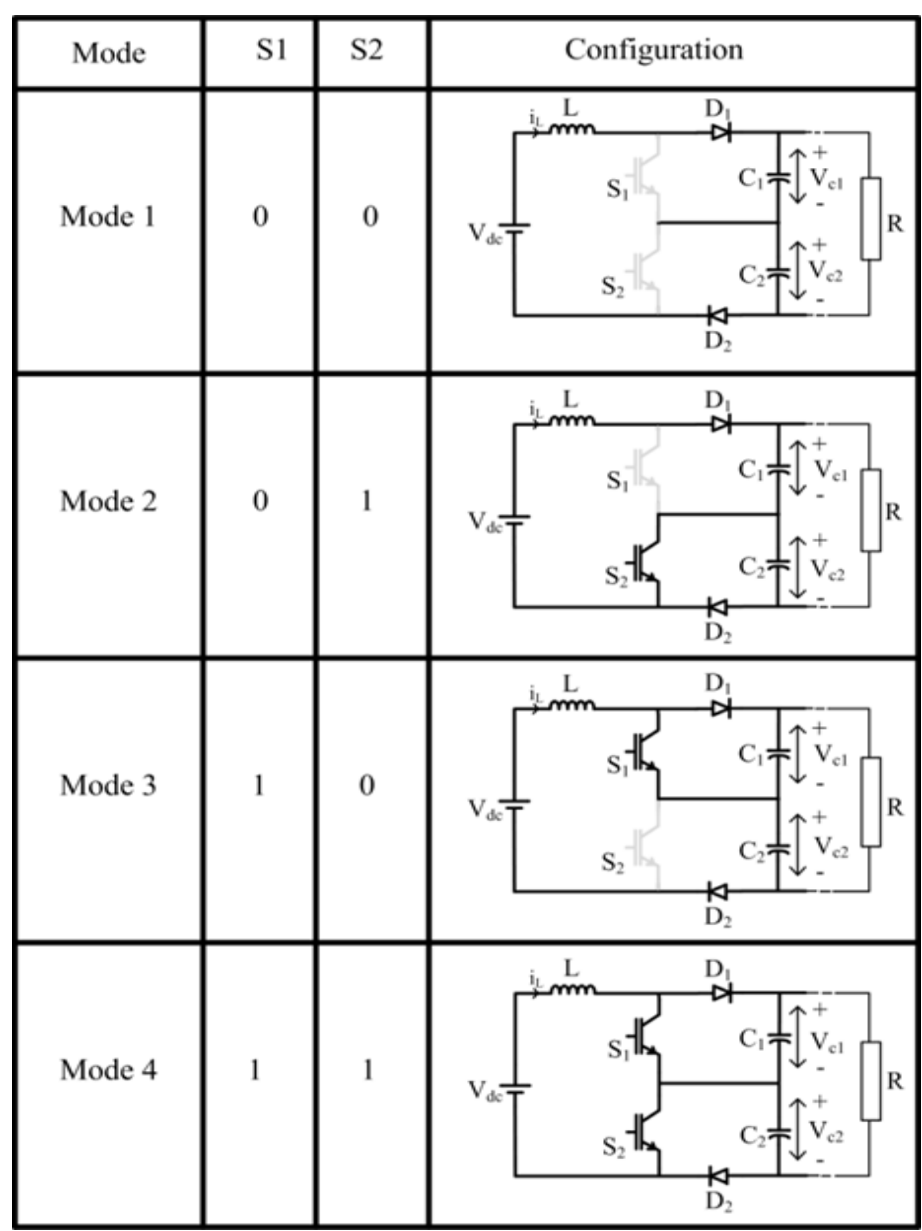

Figure 4. Modes of operation: TLBC

\subsection{Control Algorithm for TLBC (Output side Converter):}

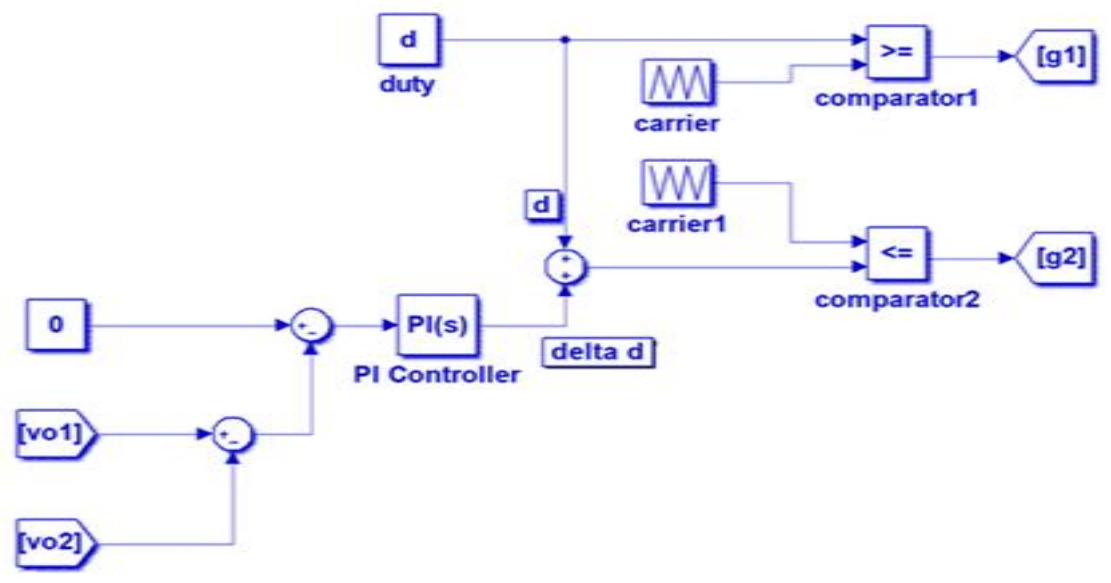

Figure 5. control algorithm for TLBC

The voltage across the capacitor $\mathrm{C} 1$ and $\mathrm{C} 2$ may become unbalance due to the timing irregularities and component tolerances and this effect can be minimized by implementing a supplemental voltage balanced control algorithms. In this the error signal is generated based on the computation of voltage across lower and upper capacitor banks and also compared with zero valued signal and this in turn fed to proportional and integral controller.

The incremental change in duty cycle $\Delta \mathrm{d}$ is generated from a controller and this is added to the calculated value of duty cycle " $\mathrm{d}$ ". The resultant modulating signal with the new value of duty cycle $(\mathrm{d}+\Delta \mathrm{d})$ is compared with the $180^{\circ}$ carrier signal and these signals are provided to the lower switch. 
The gate pulses for the upper switch is generated by comparing $0^{0}$ carrier signal with duty cycle (d) Simultaneously both voltage balance and boosting operations are obtained with proposed control algorithm by suitable selecting the " $\mathrm{d}$ " values.

\section{Simulation results:}

Table 1. Simulation parameters

\begin{tabular}{|l|l|}
\hline Peak Amplitude & $110 \mathrm{~V}$ \\
\hline Source Resistance (Rs) & $0.5 \Omega$ \\
\hline Source Inductance (Ls) & $1 \mathrm{mH}$ \\
\hline f & $50 \mathrm{~Hz}$ \\
\hline fsw & $10 \mathrm{kHz}$ \\
\hline Ts & $2 \mu \mathrm{S}$ \\
\hline (ESR) & $0.1 \Omega$ \\
\hline L & $6 \mathrm{mH}$ \\
\hline Cdc,C1 and C2 & $4700 \mu \mathrm{F}$ \\
\hline Load resistance (R) & $100 \Omega$ \\
\hline Duty cycle (d) & 0.8 \\
\hline
\end{tabular}

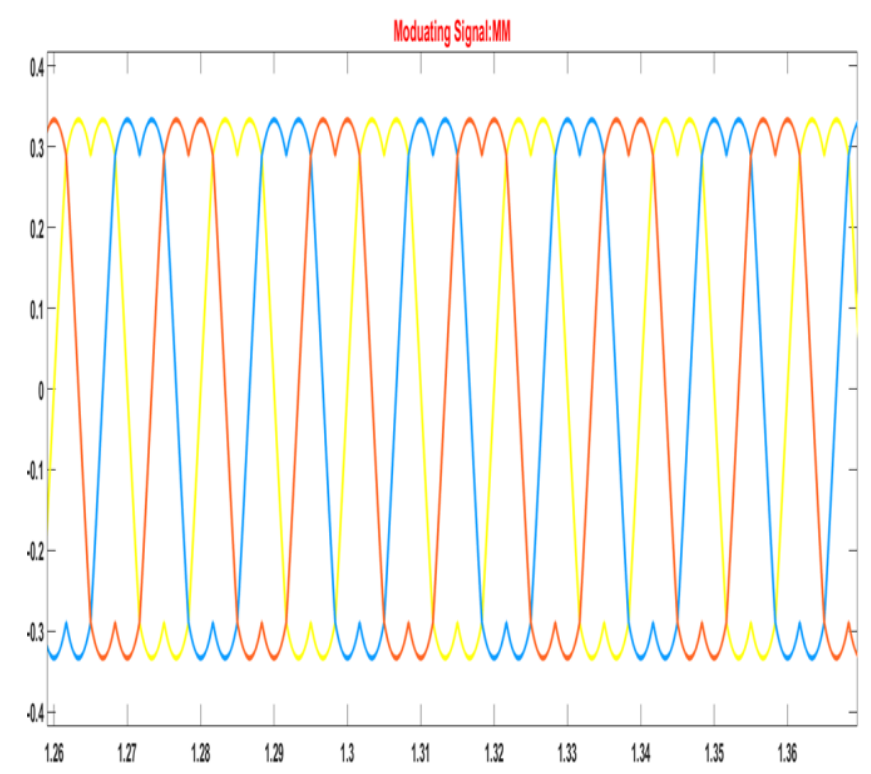

Figure 6. Output of Modulating signal (input side converter) 


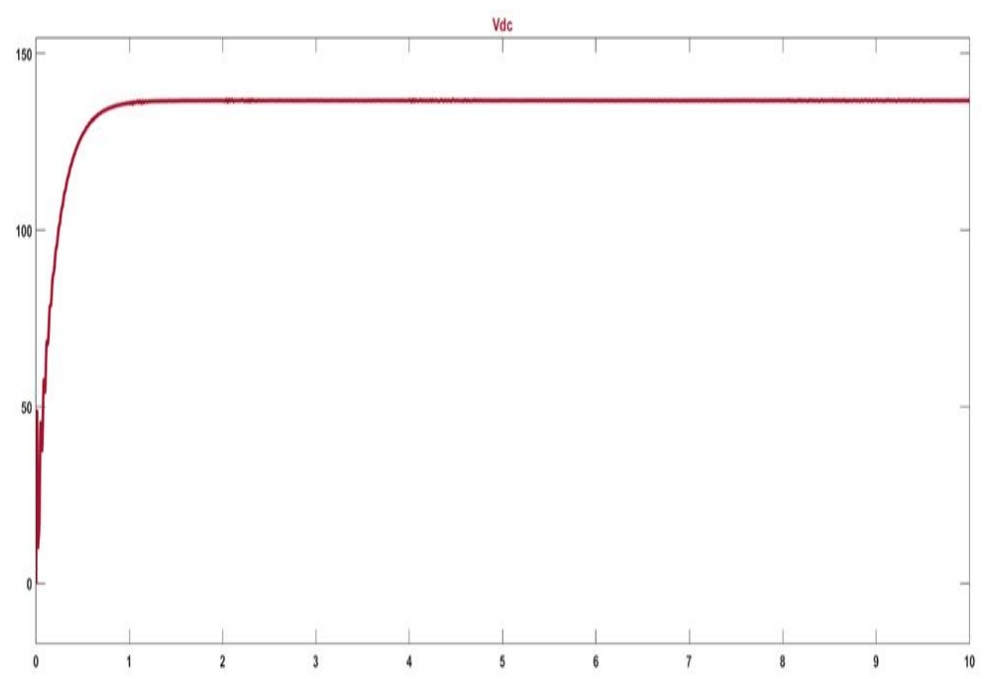

Figure 7. Output Voltage of input converter (Vdc=136.7 Volts)
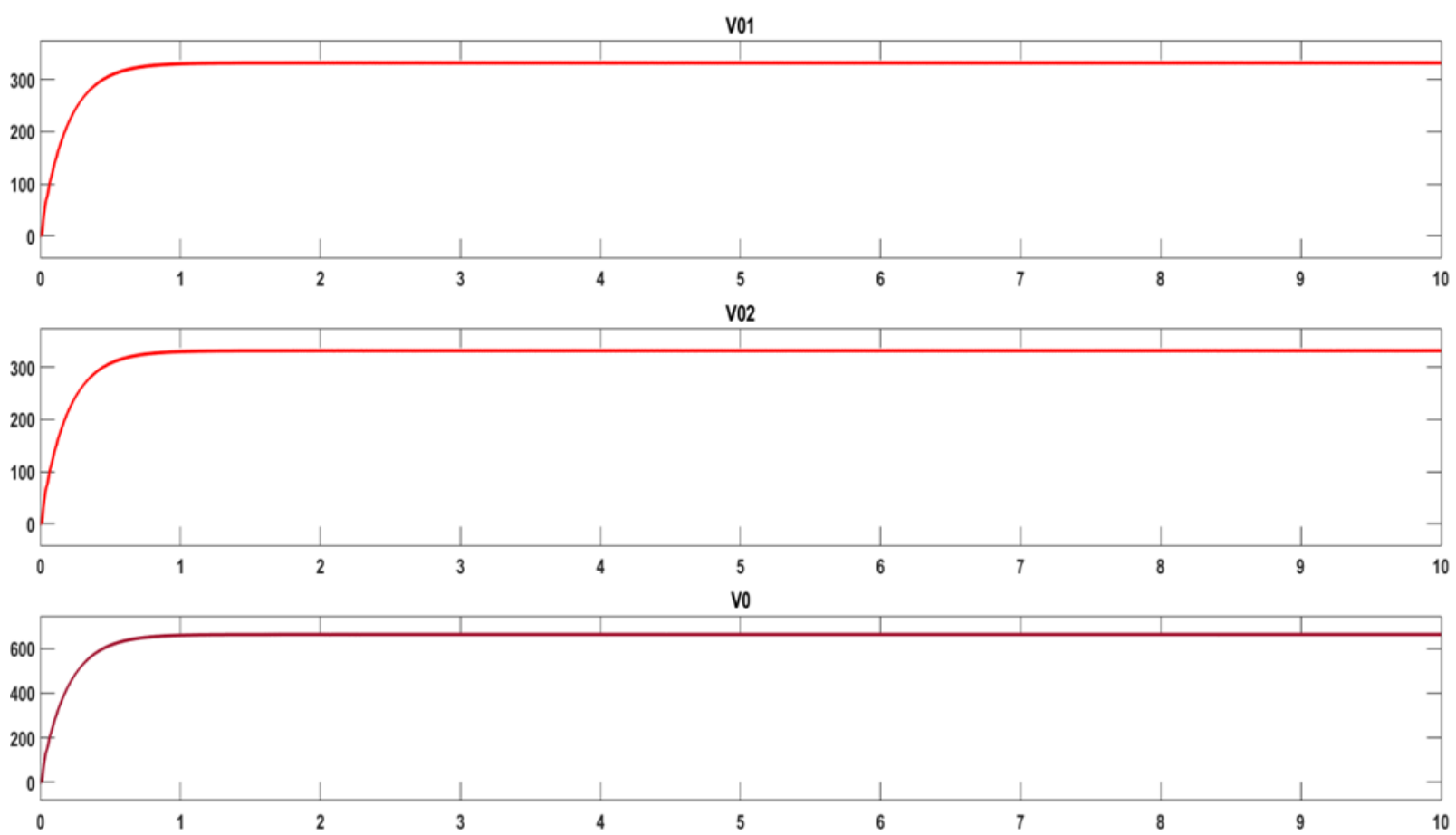

Figure 8. Outputs of Vo1, Vo2 and Vo (V01=331.5 Volts $=\mathrm{V} 02, \mathrm{~V} 0=663$ Volts)

\section{Conclusion}

The proposed MM control algorithm improves the dynamic and steady state responses of the given system by properly selecting the duty cycle and gain values.It also helps to improve the DC link voltage to a higher level at low switching frequency in the conversion of AC-DC-TLBC.This topology can be used in the application of bipolar micro grid. The three level converter can also be boosted to a higher level along with good voltage balance operation. The desired output results has been obtained in the MATLAB /Simulink environment.

\section{References}

1. A roulanandam VV, Latchoumi TP, Balamurugan K, Yookesh TL. (2020) Improving the Energy Efficiency in Mobile Ad-Hoc Network Using Learning-Based Routing, Revue d'Intelligence Artificielle, Vol 34(3), pp. 337-343, 2020.

2. Arunkarthikeyan K., and Balamurugan K. (2021) Experimental Studies on Deep Cryo Treated Plus Tempered Tungsten Carbide Inserts in Turning Operation. In: Arockiarajan A., Duraiselvam M., Raju R. (eds) Advances in Industrial Automation and Smart Manufacturing. Lecture Notes in Mechanical Engineering. Springer, Singapore. https://doi.org/10.1007/978-981-15-4739-3_26 
3. Arunkarthikeyan, K. and Balamurugan, K., (2020) July. Performance improvement of Cryo treated insert on turning studies of AISI 1018 steel using Multi objective optimization. In 2020 International Conference on Computational Intelligence for Smart Power System and Sustainable Energy (CISPSSE) (pp. 1-4). IEEE.

4. Balamurugan K. (2020) Metrological changes in surface profile, chip, and temperature on end milling of M2HSS die steel. International Journal of Machining and Machinability of Materials, 22(6):pp. 443-453.

5. Balamurugan K and Uthayakumar M, (2017) Preparation And Machining Studies Of Lapo4 Y2o3 Ceramic Matrix Composite, http://hdl.handle.net/10603/166221.

6. Balamurugan K, Uthayakumar M, Sankar S, Hareesh US, Warrier KG. (2020) Process optimisation and exhibiting correlation in the exploitable variable of AWJM. International Journal of Materials and Product Technology, 61(1), pp.16-33.

7. Balamurugan K, Uthayakumar M, Sankar S, Hareesh US, Warrier KG. (2018) Preparation, characterisation and machining of LaPO4-Y2O3 composite by abrasive water jet machine. International Journal of Computer Aided Engineering and Technology, 10(6), pp.684-697.

8. Bhasha, A.C., Balamurugan, K. (2020) End mill studies on Al6061 hybrid composite prepared by ultrasonic-assisted stir casting. Multiscale and Multidiscip. Model. Exp. and Design, https://doi.org/10.1007/s41939-020-00083-1

9. Chinnamahammad bhasha A, and Balamurugan, K. (2020) Fracture analysis of fuselage wing joint developed by aerodynamic structural materials." Materials Today: Proceedings, Vol.38, pp. 2555-2562.

10. ChinnamahammadBhasha, A., Balamurugan, K. (2020) Studies on Al6061nanohybrid Composites Reinforced with SiO2/3x\% of TiC -a Agro-Waste. Silico,. https://doi.org/10.1007/s12633-020-00758-x

11. Chinnamahammad Bhasha and Balamurugan K, (2020) Multi-objective optimization of high-speed end milling on Al6061/ 3\% RHA/ 6\% TiC reinforced hybrid composite using Taguchi coupled GRA, International Conference on Computational Intelligence for Smart Power System and Sustainable Energy (CISPSSE), Keonjhar, India, 2020, pp. 1-6, doi: 10.1109/CISPSSE49931.2020.9212295.

12. Deepthi T, and Balamurugan K. (2019) Effect of Yttrium (20\%) doping on mechanical properties of rare earth nano lanthanum phosphate (LaPO4) synthesized by aqueous sol-gel process. Ceramics International. 45(15), pp.18229-18235.

13. Dubey, A., Santoso, S., Cloud, M. P. (2013) Average-value model of electric vehicle chargers, "IEEE Transactions on Smart Grid, 4 (3):1549-1557.

14. Ezhilarasi TP, Dilip G, Latchoumi TP, Balamurugan K. (2020) UIP-A Smart Web Application to Manage Network Environments. InProceedings of the Third International Conference on Computational Intelligence and Informatics, pp. 97-108. Springer, Singapore.

15. Garikipati P, and Balamurugan K. (2021) Abrasive Water Jet Machining Studies on AlSi 7+ 63\% SiC Hybrid Composite. InAdvances in Industrial Automation and Smart Manufacturing, pp. 743-751, Springer, Singapore.

16. Garikapati P, Balamurugan K, Latchoumi TP, Malkapuram R. (2020) A Cluster-Profile Comparative Study on Machining AlSi 7/63\% of SiC Hybrid Composite Using Agglomerative Hierarchical Clustering and K-Means. Silicon. https://doi.org/10.1007/s12633-020-00447-9

17. Hui, SY., Chung, S-H., Yip, S-C. (2000) A bidirectional AC-DC power converter with power factor correction. IEEE Trans Pow Elec. 15(5):942-949.

18. Kowstubha Palle, Bhanuchandar, A., (2020) A Novel Modified Voltage Oriented Control of an Active Front-End Rectifier used for PMSG based Wind Turbine Systems, IJITEE, 9(8), ISSN- 2278-3075.

19. Lago, J., Moia, J., Heldwein, M. L. (2011) Evaluation of power converters to implement bipolar DC active distribution networks dc-dc converters, in Proc. IEEE Energy Converso Congr. Expo., Phoenix, AZ, : 985-990.

20. Latchoumi TP, Reddy MS, Balamurugan K. (2020) Applied Machine Learning Predictive Analytics to SQL Injection Attack Detection and Prevention. European Journal of Molecular \& Clinical Medicine.;7(02), pp. 3543-3553.

21. Pavan MV, Balamurugan K, Balamurugan P. (2020) Compressive test Fractured Surface analysis on PLA-Cu composite filament printed at different FDM conditions. InIOP Conference Series: Materials Science and Engineering, Vol. 988,pp. 012019. IOP Publishing.

22. Takahashi, I., Hori, K. (1995) Single phase rectifier having small input harmonic current. IEE Jpn Trans Ind Appl. 115-D (10):1215-1220.

23. Tavakoli, S. D., Khajesalehi, J., Hamzeh, M., Sheshyekani, K. (2016) Decentralized voltage balancing in bipolar dc microgrids equipped with trans-z-source interlinking converter, IET, Renewable Power Generation, 10:. 703-712.

24. Zhong, Q.-C., Hornik, T. (2013) Control of Power Inverters in Renewable Energy and Smart Grid Integration. Wiley-IEEE Press, 2013. 